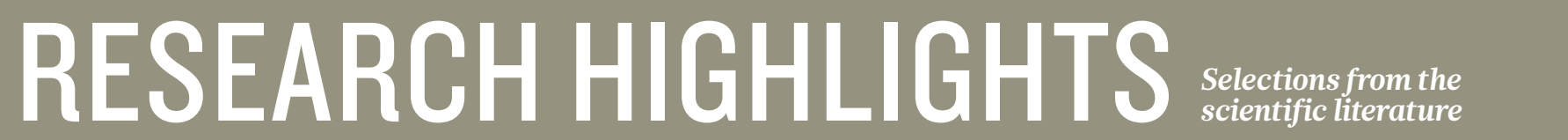

NEUROSCIENCE

\section{Blind mice can sense light}

A small molecule restores light sensitivity to blind mice when it is injected into their eyes.

Richard Kramer at the University of California, Berkeley, and his colleagues studied a mouse model of retinitis pigmentosa - a form of blindness in which light-sensing rod and cone cells in the retina degenerate. The researchers applied the molecule, AAQ, to retinas isolated from the mice and found that it triggered retinal ganglion cells - most of which are normally light-insensitive - to increase their firing rate in response to light. Other work has suggested that the molecule functions by blocking potassium ion channels in the membranes of neurons, boosting their excitability. In behavioural tests, blind mice treated with AAQ showed signs of light sensitivity.

The use of this and related molecules could restore vision less invasively than other proposed methods, the researchers say.

Neuron 75, 271-282 (2012)

\section{MICROBIOLOGY}

\section{Skin bacteria boost immunity}

Microbes living in mammalian guts have an important role in intestinal immunity and it seems that those living on the skin are similarly crucial for tuning immune responses to skin pathogens.

Yasmine Belkaid at the US National Institute of Allergy and Infectious Diseases in Bethesda, Maryland, and her colleagues compared mice with microbes on their skin with germ-free mice raised in aseptic conditions. T cells,

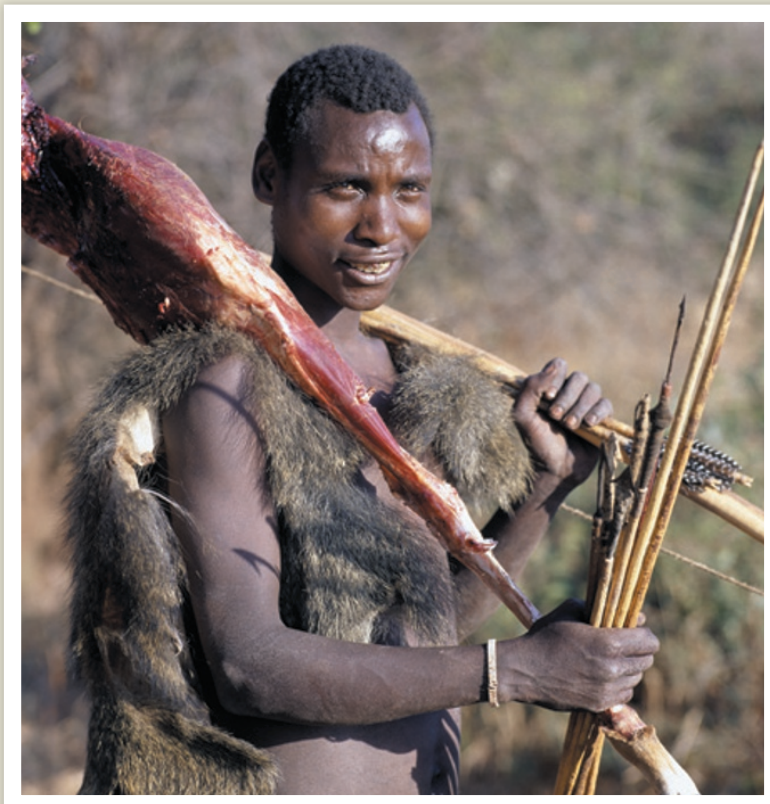

\section{GENOMICS}

\section{Hunter-gatherer genes}

Three African populations that rely mainly on hunting and gathering possess a trove of previously unrecorded genetic diversity.

Sarah Tishkoff at the University of Pennsylvania in Philadelphia and her team sequenced the full genomes of five individuals from each of three populations: Cameroonian Pygmies, and the Hadza (pictured) and Sandawe people from Tanzania. The researchers' trawl uncovered 13.4 million variants - more than 3 million of which have never been seen before.

Genes involved in immunity, metabolism, taste, smell and reproduction seem to have evolved since the different populations split - a sign of adaptation to local environments. In the Pygmies, recent changes in genes involved in the function of the pituitary gland, which secretes growth and other hormones, could explain their short stature. All the hunter-gatherers sampled showed signatures of gene flow from now-extinct human species. This has been seen before mainly in non-African populations, supporting the idea that breeding between various human species occurred regularly.

Cell http://dx.doi.org/10.1016/j.cell.2012.07.009 (2012)

For a longer story on this research, see go.nature.com/ss7rzr

a subset of immune cells, produced fewer immunestimulating molecules in germ-free animals than in control mice. When infected with a skin parasite, the germfree mice developed a greater number of parasites per skin lesion than the controls, and also showed impaired T-cell responses. Populating the skin with a skin bacterium restored immunity to the germ-free animals.

Science http://dx.doi. org/10.1126/science.1225152 (2012)

For a longer story on this research, see go.nature.com/8ahyc3

\section{ELECTROCHEMISTRY}

\section{Rechargeable Li-air battery}

Lithium-air batteries promise to greatly exceed the energy-storage capacity of conventional lithium-ion batteries and a study shows that they can retain $95 \%$ of their capacity even after 100 recharges.

Current is generated in lithium-air batteries when lithium ions from the anode react with oxygen from the air - rather than with a limited volume of oxidizing agent, as in conventional batteries. Peter Bruce and his colleagues at the University of St Andrews, UK, created a lithium-air battery using an electrolyte of dimethylsulphoxide, through which the lithium ions flow, and a porous gold cathode where oxygen is reduced before it reacts with the lithium ions. These materials seem to prevent the sidereactions that have quickly degraded the performance of previous lithium-air batteries. Science http://dx.doi.

org/10.1126/science.1223985 (2012)

\section{ANIMAL BEHAVIOUR}

\section{Sex is costly for squid}

For a squid, mating can take up to three hours, and the resulting energy losses could put the animal at a disadvantage around predators and reduce 